VNU Journal of Science: Natural Sciences and Technology

Journal homepage: https://js.vnu.edu.vn/NST

Original Article

\title{
Morphological and Histological Characteristics of Testis of the Goby Glossogobius sparsipapillus Living from Coastal Estuaries from Bac Lieu to Ca Mau
}

\author{
Nguyen Huu Duc Ton, Nguyen Thi Thuy Hien, Tran Chi Canh, Dang Hoa Thao, \\ Nguyen Thi Nha Y, Dinh minh Quang*
}

Can Tho University, 3/2 Street, Xuan Khanh Ward, Ninh Kieu Distrit, Can Tho City, Vietnam

Received 06 October 2019

Revised 07 December 2019; Accepted 11 December 2019

\begin{abstract}
This study was conducted in the coastal estuaries in Bac Lieu and Ca Mau provinces in order to provide data on morphological and histological characteristics of as well as the spermatocyte development at every stage of the development of testis of goby Glossogobius sparsipapillus. The analysis results of 226 fish individuals, collected monthly from April 2019 to September 2019 by using the bottom nets, showed that the testis of this fish was double strands. In stage I, testis was small, thin and transparent; and the weight and size of testis increased from that stage onward. The colour of the testis became ivory white with the smooth and puffed surface. Spermatogonia were found through the cross-section of the testis in stage I, and then they were divided into primary spermatocytes and secondary spermatocytes, which were interlaced in stage II. In stage III, spermatids appeared in testicular lobes and developed into sperm in stage IV. This fish species is a multiple spawner during the breeding season, because there are several developmental stages of spermatocytes in their histology. This result is the basis for further research on artificial reproduction of this fish.
\end{abstract}

Keywords: Bac Lieu, Ca Mau, Glossogobius sparsipapillus, reproductive form, testis.Keywords: Essential oil plats, life form, plants, Sop Cop nature reserve.

\footnotetext{
* Corresponding author.

Email address: dmquang@ctu.edu.vn

https://doi.org/10.25073/2588-1140/vnunst.4958
} 


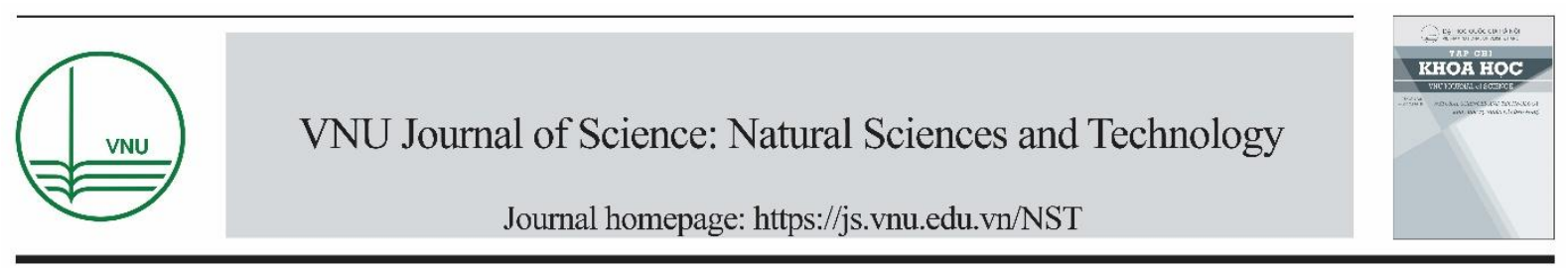

\title{
Đặc điểm hình thái và cấu trúc mô học của tinh sào ở cá bống cát Glossogobius sparsipapillus ở vùng cửa sông ven biển Bạc Liêu và Cà Mau
}

\author{
Nguyễn Hữu Đức Tôn, Nguyễn Thị Thúy Hiền, Trần Chí Cảnh, Đặng Hòa Thảo, \\ Nguyễn Thị Nhã Ý, Đinh Minh Quang*
}

Truờng Đại học Cần Tho, Đuò̀ng 3/2, phưòng Xuân Khánh, Quận Ninh Kiều, TP Cần Tho, Việt Nam

Nhận ngày 06 tháng 10 năm 2019

Chỉnh sửa ngày 07 tháng 12 năm 2019; Chấp nhận đăng ngày 11 tháng 12 năm 2019

\begin{abstract}
Tóm tắt: Đề tài nghiên cứu này được tiến hành ở vùng cửa sông ven biển Bạc Liêu và Cà Mau nhằm cung cấp dẫn liệu về đặc điểm hình thái và cấu trúc mô học của tinh sào cũng như sự phát triển tinh bào theo từng giai đoạn phát triển của tinh sào ở cá bống cát Glossogobius sparsipapillus. Kết quả phân tích từ 226 mẫu cá thu được mỗi tháng từ 4/2019 đến 9/2019 bằng lưới đáy cho thấy tinh sào của cá bống cát có dạng sợi kép. Ở giai đoạn I, tinh sào có dạng sợi mảnh, nhỏ, dẹp, gần như trong suốt; càng về sau thì tinh sào ngày càng tăng về khối lượng cũng như kích thước. Màu sắc của tinh sào chuyển dần sang màu trắng ngà, bề mặt trơn láng, căng phồng. Thông qua lát cắt ngang tinh sào thấy được các tinh nguyên bào tập trung ở giai đoạn I, sau đó phân chia để tạo thành các tinh bào thời kì 1 và 2 xen lẫn nhau ở giai đoạn II. Đến giai đoạn III, tinh sào bắt đầu xuất hiện tinh tử trong các thùy; các tinh tử biệt hóa thành tinh trùng xuất hiện tại giai đoạn IV của quá trình. Loài cá này thuộc nhóm cá đẻ nhiều đợt trong mùa sinh sản do mô học của chúng tồn tại nhiều giai đoạn phát triển khác nhau của tinh bào. Kết quả này là cơ sở cho nghiển cứu tiếp theo về sinh sản nhân tạo loài cá này.
\end{abstract}

Tù khóa: Bạc Liêu, Cà Mau, Glossogobius sparsipapillus, hình thức sinh sản, tinh sào.

\section{1. Đặt vấn đề}

Cá bống cát Glossogobius sparsipapillus được mô tả đầu tiên bởi Akihito \& Meguro (1976) [1], là một trong ba loài cá bống cát được ghi nhận tại Việt Nam gồm cá bống cát G. giuris (Hamilton 1822), cá bống cát G. aureus Akihito \& Meguro 1975 và cá bống cát $G$. sparsipapillus Akihito \& Meguro 1976 [2]. Theo Nguyễn Văn Hảo (2005) [3], cá bống cát G. sparsipapillus sống ở khu vực cửa sông và vào khá sâu trong hạ lưu nước ngọt của các sông lớn, thịt cá thơm ngon và giá trị kinh tế cao. Cá bống có giá trị dinh dưỡng cao hơn nhiều loài cá kinh tế khác ở biển, đặc biệt là hàm lượng mỡ (lipit) trong thịt của cá bống lớn hơn các loài cá kinh tế khác ở vịnh Bắc Bộ từ 3 đến 12 lần [4]. Chính vì vậy, ở Việt Nam, từ lâu nhân dân ta đã coi cá bống là thực phẩm quý để bồi bổ sức khỏe cho người già yếu, ốm đau [4].

\footnotetext{
* Tác giả liên hệ.

Địa chỉ email: dmquang@ ctu.edu.vn

https://doi.org/10.25073/2588-1140/vnunst.4958
} 
Hiện nay, một số nghiên cứu về loài cá bống này được thực hiện nhưng chủ yếu tập trung vào mô tả hình thái phân loại, sự phân bố $[5,6]$ quan hệ tương quan giữa chiều dài và khối lượng cá [7]. Loài cá bống cát này là một trong những loài cá có giá trị kinh tế ở khu vực ven biển Đồng bằng sông Cửu Long (ĐBSCL), nhưng hiện nay lại có rất ít thông tin về đặc điểm hình thái và cấu trúc mô học của tinh sào ở vùng cửa sông ven biển Bạc Liêu và Cà Mau. Vì vậy, đề tài "Đặc điểm hình thái và cấu trúc mô học của tinh sào ở cá bống cát Glossogobius sparsipapillus ở vùng cửa sông ven biển Bạc Liêu và Cà Mau" được thực hiện nhằm cung cấp thông tin khoa học về đặc điểm hình thái, cấu trúc mô học tinh sào và hình thức sinh sản của loài cá này ở khu vực nghiên cứu.

\section{Phương tiện và phương pháp nghiên cứu}

\subsection{Thời gian và địa điểm nghiên cưu}

Mẫu cá G. sparsipapillus được thu định kỳ mỗi tháng 1 lần từ tháng tháng 4 đến tháng 9 năm 2019 (2 lần ở mùa khô vào tháng 4 và tháng 5 ; và 4 lần ở mùa mưa vào tháng 6 đến tháng 9) tại khu vực ven biển tỉnh Bạc Liêu (Vĩnh Hậu và Đông Hải) và Cà Mau (Đầm Dơi) (Hình1).

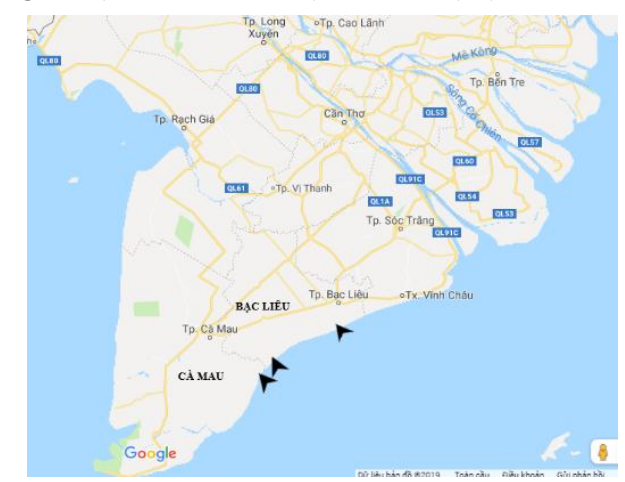

Hình 1. Sơ đồ các điểm thu mẫu cá bống cát (Dấu mũi tên: Điểm thu mẫu; nguồn: Google Map).

\subsection{Phưong pháp thu, định loại và cố định mẫu}

Mẫu cá bống cát được người dân thu ngẫu nhiên với nhiều kích thước khác nhau bằng lưới đáy với mắt lưới $2 \mathrm{a}=1,5 \mathrm{~cm}$. Sau khi thu mẫu, mẫu cá được lưu trữ trong dung dịch formol $4 \%$ sau đó đem về phòng thí nghiệm Động vật, Bộ môn Sư phạm Sinh học, Khoa Sư phạm, Trường Đại học Cần Thơ.

\subsection{Phuơng pháp phân tích và xử lý số liệu}

Tại phòng thí nghiệm Động vật, dựa theo mô tả của Nguyễn Văn Hảo (2005) [3] để định loại mẫu cá. Phân biệt giới tính của cá dựa vào đặc điểm hình thái của gai sinh dục (hình tam giác nhọn là cá đực và oval là cá cái), đo các chỉ tiêu bên ngoài của cá trước khi giải phẫu để lấy tinh sào như: đo chiều dài tổng và chiều dài chuẩn (TL; $0,1 \mathrm{~cm})$, đo chiều cao thân, dài đầu, rộng miệng và xác định khối lượng (W; $0,01 \mathrm{~g})$. Theo mô tả của Nikolsky (1963) [8], các giai đoạn phát triển tinh sào được chia thành 6 bậc thành thục sinh dục. Các tinh sào sau khi được lấy ra và xác định giai đoạn sẽ chứa trong dung dịch formol $4 \%$ để tiến hành làm tiêu bản mô học tinh sào.

Tiêu bản hiển vi cố định tinh sào cá bống cát được tiến hành dựa trên phương pháp nhuộm màu kép của Carleton nnk. (1980) [9] và dựa trên quy trình thực hiện tiêu bản hiển vi cố định tinh sào của cá kèo vảy to Parapocryptes serperaster [10]. Theo Bùi Lai nnk. (1985) [11], các giai đoạn phát triển của tế bào tinh sào được chia thành 5 bậc phát triển. Dựa trên phương pháp nghiên cứu của Miller (1984) [12] để xác định hình thức sinh sản của cá.

\section{Kết quả nghiên cứu và thảo luận}

Kết quả phân tích giai đoạn phát triển của tinh sào của 226 mẫu cá thu được ở vùng ven biển Bạc Liêu và Cà Mau được trình bày trong Bảng 1.

Giai đoạn I: Tinh sào có dạng mảnh như sợi chỉ, nhỏ, dẹp, thon dài, gần như trong suốt nằm sát phía xương sống của thân cá, có nhiều màng bao mỏng bao phủ bên ngoài tinh sào (Hình 2a). Ở giai đoạn này khó phân biệt với noãn sào giai đoạn I khi quan sát bằng mắt thường. Do vậy, để xác định chính xác giai đoạn I của tinh sào phải kết hợp với quan sát gai sinh dục bên ngoài của cá và soi dưới kính hiển vi soi nổi . Lát cắt ngang tinh sào quan sát được nhiều tinh nguyên bào tập trung thành từng cụm nằm rãi rác khắp tinh sào và các mô liên kết xen giữa các cụm tinh nguyên bào. Không quan sát thấy ống dẫn tinh (Hình 3a). 
Bảng 1. Số lượng mẫu cá ứng với 4 giai đoạn phát triển của tinh sào thu được từ 4/2019-9/2019

\begin{tabular}{ccccccccccccccccc}
\hline Thời gian & \multicolumn{4}{c}{ Vĩnh Hậu - Bạc Liêu } & \multicolumn{4}{c}{ Đông Hải - Bạc Liêu } & \multicolumn{5}{c}{ Đầm Dơi - Cà Mau } \\
\cline { 2 - 15 } thu mâuu & T & GĐ1 & GĐ2 & GĐ3 & GĐ4 & T & GĐ1 & GĐ2 & GĐ3 & GĐ4 & T & GĐ1 & GĐ2 & GĐ3 & GĐ4 \\
\hline Tháng 4 & 12 & 1 & 6 & 5 & 0 & 22 & 0 & 9 & 9 & 4 & 27 & 14 & 12 & 1 & 0 \\
Tháng 5 & 1 & 0 & 0 & 1 & 0 & 10 & 1 & 4 & 4 & 1 & 11 & 0 & 2 & 5 & 4 \\
Tháng 6 & 11 & 7 & 0 & 2 & 2 & 5 & 0 & 1 & 3 & 1 & 9 & 0 & 0 & 7 & 2 \\
Tháng 7 & 5 & 3 & 2 & 0 & 0 & 7 & 0 & 0 & 6 & 1 & 15 & 1 & 0 & 9 & 5 \\
Tháng 8 & 12 & 3 & 5 & 2 & 2 & 10 & 0 & 2 & 3 & 5 & 13 & 0 & 4 & 2 & 7 \\
Tháng 9 & 21 & 0 & 8 & 10 & 3 & 22 & 0 & 1 & 8 & 13 & 13 & 0 & 8 & 3 & 2 \\
\hline
\end{tabular}

Ghi chú: T: Tổng mẫu cá thu đươc, GĐ1, GĐ2, GĐ 3 và GĐ 4 lần luợt là số lượng mẫu cá thu được ứng với tinh sào giai đoạn I, II, II và IV

Giai đoạn II: Tinh sào có kích thước lớn hơn giai đoạn $\mathrm{I}$ (bề ngang gần như gấp đôi so với giai đoạn $\mathrm{I}$ ), dài, dẹp, bề mặt trơn láng, có màu trắng đục (Hình 2b). Ở giai đoạn này có thể phân biệt với noãn sào bằng mắt thường. Lát cắt ngang ở giai đoạn này thấy được tinh nguyên bào đã phát triển thành tinh bào thời kì 1 và một số đã phát triển thành tinh bào thời kì 2 . Các tinh bào này có kích thước nhỏ, phân bố đan xen với các cụm tinh nguyên bào. Tinh bào thời kì 1 nhỏ hơn tinh nguyên bào, có nguồn gốc từ tinh nguyên bào, hạt nhân bắt màu mạnh với thuốc nhuộm hematocylin. Tinh bào thời kì 2 có một vài sự khác nhau về hình dạng, chúng nhỏ hơn những tinh bào thời kì 1 và nhân bắt màu ít hơn với thuốc nhuộm (Hình 3b).
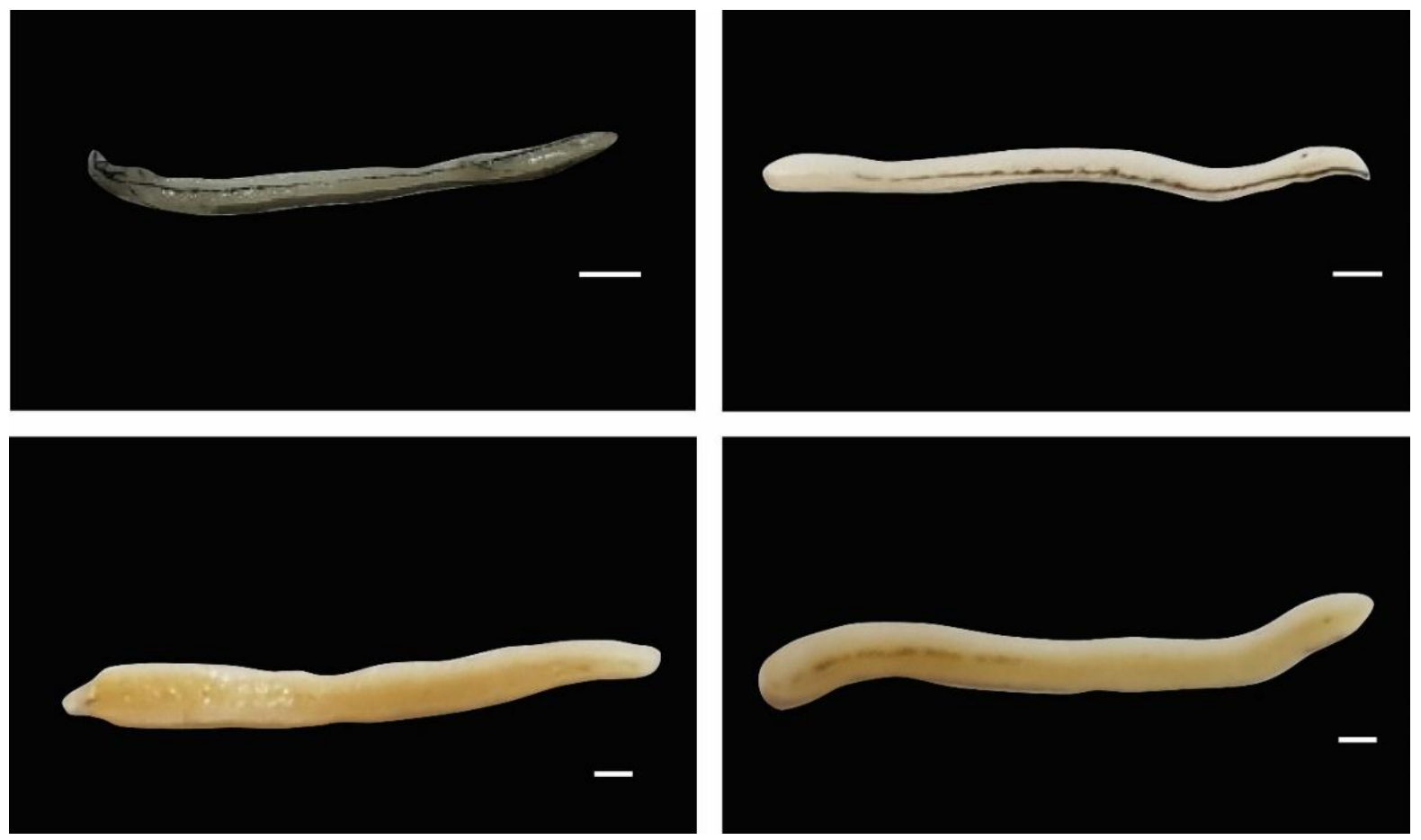

Hình 2. Hình thái ngoài của tinh sào cá bống cát (a, b, c, d lần lượt là tinh sào giai đoạn I, II, III, IV; thước tỉ lệ 1mm). 
Giai đoạn III: Tinh sào gia tăng kích thước (bề ngang gần như gấp đôi so với giai đoạn II), dài, bề mặt trơn láng, một mặt phẳng, một mặt hơi nhô lên, có màu trắng ngà (Hình $2 \mathrm{c}$ ). Ở giai đoạn này có thể quan sát rõ bằng mắt thường. Lát cắt ngang tinh sào ở giai đoạn này cho thấy, trong các thùy của tinh sào, xuất hiện nhiều tinh bào thời kì 2 xen lẫn với tinh bào thời kì 1 , tinh nguyên bào giảm rõ rệt. Ở giai đoạn này cũng xuất hiện tinh tử xen lẫn trong các thùy. Ống dẫn tinh được quan sát rõ ở giai đoạn này (Hình $3 c$ ).

Giai đoạn IV: Tinh sào có kích thước lớn
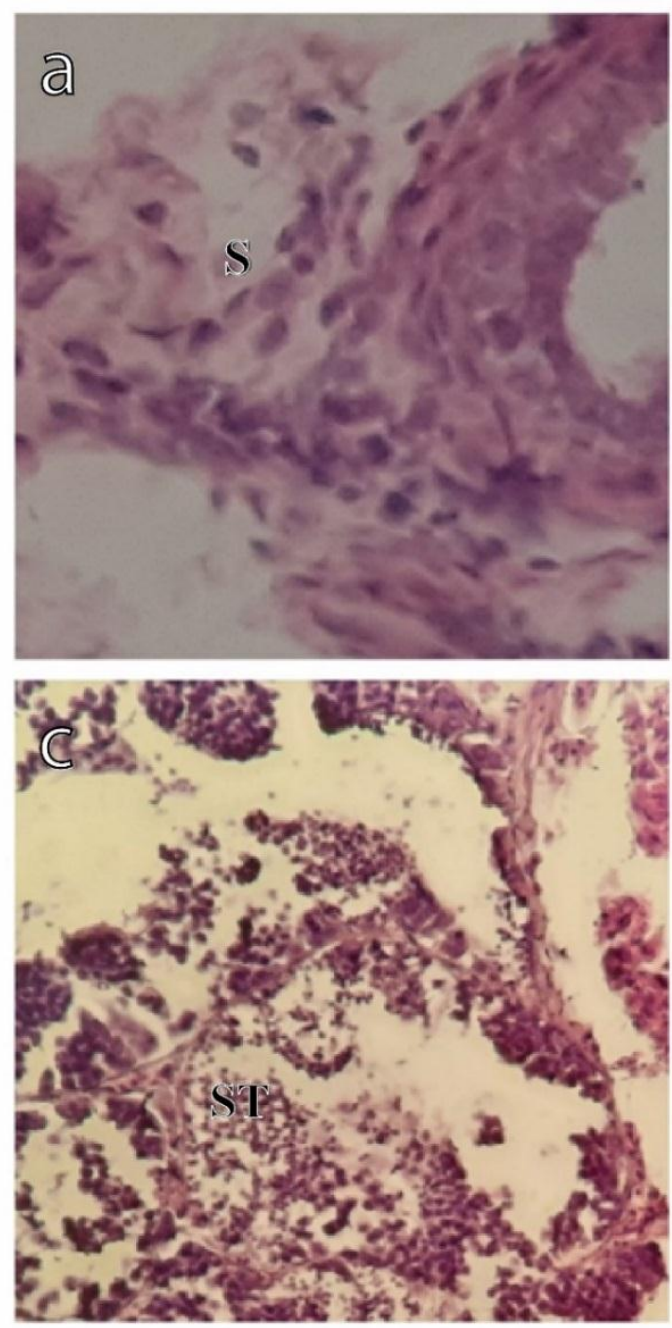

(gần như đạt cực đại), dài, bề mặt trơn láng, căng phồng, thiết diện gần giống với hình tam giác, có màu trắng ngà đục. Tinh sào đậm dần về phía đuôi, do túi tinh tăng lên rất nhiều và nằm sát nhau (Hình 2d). Mô liên kết ở giai đoạn này rất mỏng. Quan sát giai đoạn này thấy được ống dẫn tinh rất rõ, đa số các tinh tử đã biệt hóa thành các tinh trùng, phân bố thành từng cụm lớn trong các thùy. Tinh sào chứa chủ yếu là tinh trùng xen lẫn với một số ít tinh tử. Tinh trùng thấy rõ là các tế bào nhỏ có đuôi với phần đầu chứa nhân bắt màu đậm hơn (Hình 3d).
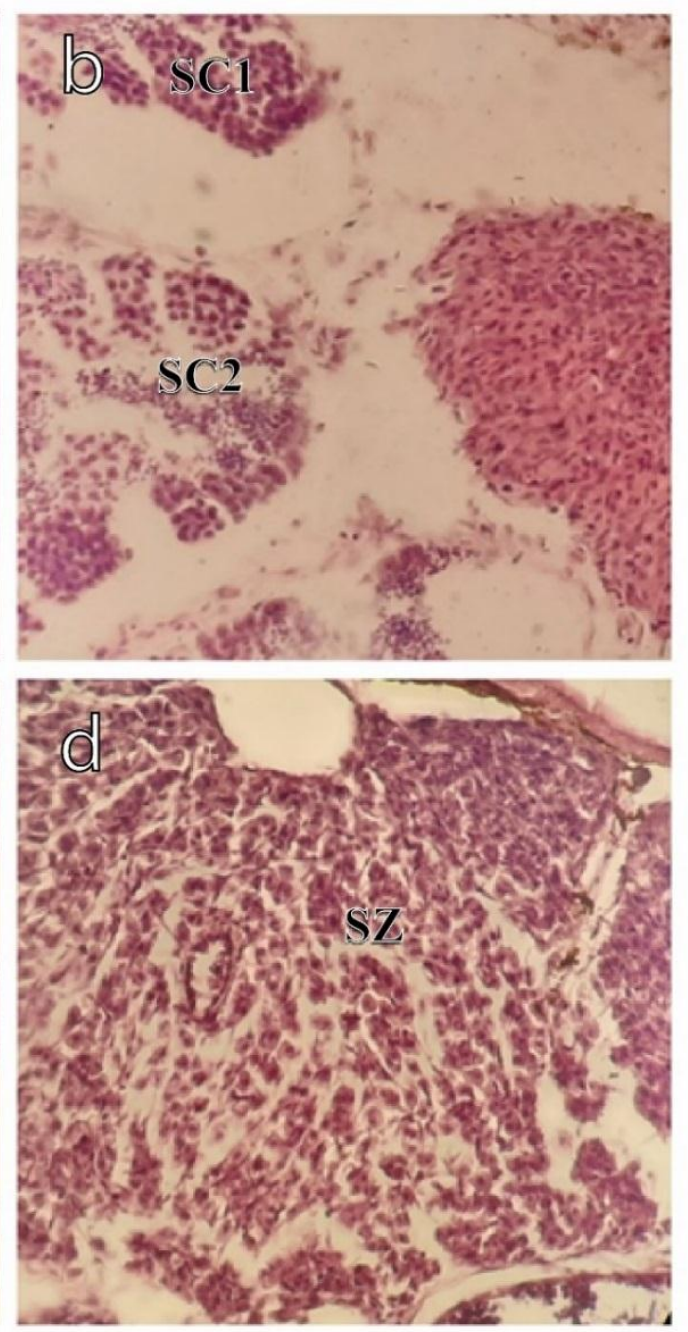

Hình 3. Lát cắt ngang tinh sào cá bống cát

(a, d, c, d lần lượt là tinh sào giai đoạn I, II, III và IV; Tinh nguyên bào (S), tinh bào thời kỳ 1 (SC1), tinh bào thời kỳ 2 (SC2), tinh tử $(\mathrm{ST})$ và tinh trùng $(\mathrm{SZ})$ ). 
Sự phát triển tinh sào ở cá bống cát trải qua các giai đoạn có sự phát triển gần như tương đồng với các loài như: cá kèo vảy to Parapocryptes serpersater [10], cá bống sao Boleophthalmus boddarti [13], và cá bống trân Butis butis [14], cá bống trứng Eleotris melanosoma [15], cá bống mít Stigmatogobius pleurostigma [16] và cá thòi lòi Periophthalmodon septemradiatus [17]. Ở giai đoạn I, hình thái ngoài gần như giống nhau ở các loài các nêu trên, với tinh sào đều mảnh, nhỏ, dẹp, nằm sát vào cột sống của cá. Ở giai đoạn IV, tinh sào đều căng phồng, càng về phía đuôi thì càng đậm màu, vì tinh trùng đã bắt đầu tập trung về nhiều và xếp sát nhau. Hình thái mô học tinh sào vào giai đoạn IV ở loài này có sự khác biệt so với các loài được nghiên cứu trước đó, ở loài cá bống cát $G$. sparsipapillus bề mặt tinh sào thì trơn láng còn ở loài cá bống trứng Eleotris melanosoma [15] bề mặt tinh sào có dạng gợn sóng. Từ tinh nguyên bào ban đầu sẽ tiến hành phân chia nguyên nhiễm để tăng số lượng, sau đó tinh bào lớn lên thành tinh bào 1 . Ở giai đoạn tiếp theo, tinh bào 1 sẽ phân chia giảm nhiễm tạo tinh bào 2, phân chia giảm nhiễm lần 2 tạo nên tinh tử và biệt hóa thành tinh trùng. Trong số những mẫu thu được trong quá trình nghiên cứu chưa phát hiện được tinh sào ở giai đoạn $\mathrm{V}$ và VI nên đặc điểm hình thái và mô học ở hai giai đoạn này chưa được mô tả. Chiều dài của cá ứng với mỗi giai đoạn cũng có sự khác nhau; sự phát triển chiều dài của cá tăng dần qua 4 giai đoạn để đến giai đoạn IV chiều dài cá đạt lớn nhất ứng với giai đoạn thành thục của cá.

\section{Kết luận}

Ở cá bống cát $G$. sparsipapillus, sự thành thục sinh dục của tinh sào thể hiện tương đối rõ ràng. Tuy tinh sào đều là dạng sợi kép, nhưng từ giai đoạn I đến giai đoạn IV có sự khác nhau rõ ràng từ màu sắc, kích thước, đến hình dạng ngoài của tinh sào. Tinh nguyên bào, tinh bào thời kì 1 , tinh bào thời kì 2 , tinh tử và tinh trùng lần lượt xuất hiện qua các giai đoạn I, II, III, IV của tinh sào. Tinh trùng chiếm hầu hết ở giai đoạn IV bên cạnh các giai đoạn khác của tinh bào, điều này cho thấy loài cá này thuộc nhóm cá đẻ tập trung nhiều đợt vào mùa sinh sản.

\section{Lò̀i cảm ơn}

Chúng tôi xin chân thành cảm ơn Trường Đại học Cần Thơ đã hỗ trợ kinh phí cho nghiên cứu này thông qua đề tài "Nghiên cứu sinh học sinh sản cá bống cát Glossogobius sparsipapillus phân bố vùng ven biển Bạc Liêu"; Mã số: TSV2019-111; và ngư dân địa phương đã hỗ trợ khâu thu mẫu.

\section{Tài liệu tham khảo}

[1] P. Akihito, K. Meguro, Glossogobius sparsipapillus, a new species of goby from Viet Nam. Japanese Journal of Ichthyology 23 (1976) 9-11.

[2] D.D. Tran, K. Shibukawa, T.P. Nguyen, P.H. Ha, X.L. Tran, V.H. Mai \& K. Utsugi, Fishes of Mekong Delta, Vietnam. Can Tho University Publisher, Can Tho, 2013 (in Vietnamese).

[3] H.V. Nguyen, Freshwater fish of Viet Nam, Vol III, Agriculture Publishing House, Ha Noi, 2005 (in Vietnamese).

[4] T.N. Nguyen, Fauna of Vietnam - Gobioidei, Science and Technics House Publishing, Ha Noi, 2000 (in Vietnamese).

[5] H.M.T. To, T.M.X. Pham, V.H. Mai, D.D. Tran. Species composition of goby (Eleotridae and Gobiidae) and some characteristics of tank goby (G. giuris) distributed in Can Tho. Proceeding of Aqua Youth, Ho Chi Minh City (2013) 575-582 (in Vietnamese).

[6] X.M.T. Pham, D.D. Tran, Some characteristics on reproductive biology of Tank goby (Glossogobus giuris) distributed in Can Tho city, Can Tho University Journal of Science 27 (2013) 161-168 (in Vietnamese).

[7] Q.M. Dinh, T.V. Ly. Preliminary study result of length - weight of tank goby, Glossogobius giuris, distributing in Soc Trang, Can Tho University Journal of Science 2 (2014) 220-225. (in Vietnamese).

[8] G.V. Nikolsky, Ecology of fishes, Academic Press, London, United Kingdom, 1963.

[9] H.M. Carleton, R.A.B. Drury, E. Wallington, Carleton's Histological Technique, Oxford University Press, London, United Kingdom, 1980.

[10] Q.M. Dinh, J.G. Qin, S. Dittmann, D.D. Tran, Reproductive biology of the burrow dwelling goby Parapocryptes serperaster. Ichthyological 
Research 63 (2016) 324-32. https://doi.org/ 10.1007/s10228-015-0502-7

[11] L. Bui, M.H. Nguyen, Q.K. Nguyen, Q.L. Le, D.Y. Mai, Basis of physiology of fish. Agriculture Publishing House, Ha Noi, 1985 (in Vietnamese).

[12] P.J. Miller, The topology of gobioid fishes, G.W. Potts, R.J. Wootton (eds), The topology of gobioid fishes, Academic Press, Orlando, London, United Kingdom, 1984, 119-53

[13] Q.M. Dinh, T.T.G. Nguyen, T.K.T. Nguyen, Reproductive biology of the mudskipper Boleophthalmus boddarti in Soc Trang. Tap chi Sinh hoc 37 (2015) 362-9. https://doi.org/10. 15625/0866-7160/v37n3.6720

[14] Q.M. Dinh, T.T.M. Le, Reproductive traits of the duckbill sleeper Butis butis (Hamilton, 1822). Zoological Science 34 (2017) 452-8. https://doi. org/10.2108/zs170013.
[15] N.H.T. Le, Q.M. Dinh, Reproductive pattern, morphological and histological characteristics of gonads of the goby Eleotris melanosoma from the Coastline in Soc Trang, VNU Journal of Science: Natural Sciences and Technology, 33 (2017) 9-86. http://doi.org/10.25073/2588-1140/ vnunst.4490 (in Vietnamese).

[16] Q.M. Dinh, T.T.N. Tran, Reproductive biological traits of the goby Stigmatogobius pleurostigma (Bleeker, 1849) from the Mekong Delta, Vietnam. Indian Journal of Fisheries 65 (2018) 20-5. http://doi.org/10.21077/ijf.2018.65.1.681 88-04.

[17] Q.M. Dinh, L.T. Tran, N.C. Ngo, T.B. Pham, T.T.K. Nguyen, Reproductive biology of the unique mudskipper Periophthalmodon septemradiatus living from estuary to upstream of the Hau River. Acta Zoologica, 2018, 1-12. http://doi.org/10.1111/azo.12286. 